Ученые записки Крымского федерального университета имени В. И. Вернадского

Юридические науки. - 2021. - Т. 7 (73). № 1. - С. 49-56.

УДК 67.3

DOI: $10.37279 / 2413-1733-2021-7-1-49-56$

\title{
FACTORS OF EMERGING STATEHOOD IN THE SOUTH-WEST ASIA IN NEOLITHIC - CHALCOLITHIC
}

\author{
Koshman V.A. \\ ФГБОУ ВО «Российский государственный университет правосудия»
}

\begin{abstract}
It is stated that the process of initial statehood formation occurred in the North Mesopotamia. Also some statements around ascension of sedentariness and pastoralism are revised in the article. Author highlights key problems of population estimations in ancient times of the South-West Asia. New data in the article corrects population estimations by degree. One of the leading themes in the paper is the role of highly mobile part of population in functioning of interregional trade. It is emphasized that Uruk phenomenon is highly overestimated and lacks hard evidence. Author presents new approach of understanding the statehood origin. It is made on the basis of material data and careful review of archaeologic interpretations.
\end{abstract}

Key words: neolitization, statehood, South-West Asia, Uruk expansion, Halaf, semi-nomads, Iranian plateau.

The question about the origin of inequality, private property, and the state has always been attracted to the special attention of philosophers, historians and other people who are interested in the beginnings of the organization of modern society. The most ancient archeological finds connected with sedentarization, pastoralism, and farming were made on the territory of the Middle East. That is why that territory is of particular interest to researchers. The processes which were going on there become a basis for the theoretic and intercultural framework.

Consequently, exploring of occurrence above-mentioned things, their relationship, and their influence on the dynamics of social structure are necessary. Accordingly, in this article, we will analyze archeological evidence gained in recent decades and try to submit renewed reasoning and conclusions about the emergence and development of statehood of the Middle East.

Any consideration of the origin of inequality begins with the Neolithic revolution - the term which was developed by G. Child. This represents a sedentarization together with the emergence of pastoralism and farming, which led to rapid and fundamental change. However, half a century has passed since the introduction of the term and during that period, the overall picture of the process has been detailed significantly. As a result, the term «Neolithic revolution» was changed to «neolitization». This implies a lengthy and multiilinear process of mutual adaptation of humans, animals, and plants. One of its aspects is a division of processes of settlement, domestication of animals and plants as different processes. To understand it better, here is an example: the first sedentary settlements in the Levant and Anatolia were inhabited by hunter-gatherers in the Mesolithic period. The other example is ceramic. As a rule, its emergence is related to a settled way of life: at this time the first ceramic with estimates ranging from 12 to 18 thousand years ago was found on the territory of China, Russian Priamurye, and sites of early Jomon period on the Japanese islands [1]. 
Consequently, a whole set of the Neolithic technological integrated complex as such didn't exist originally. Technological components are a diachronic phenomenon. However, it could be identified in the Middle East by the turn of VII millennium B.C. But for further development, all signs aren't necessary. For instance, in Mesoamerica pastoralism hadn't arisen at all and in the Americas, ceramic hadn't been in demand for a long time because of the existence of the bottle gourd. Nevertheless, all of these technological components played a part in the process of the increasing complexity of society.

One of the consequences of settlement and plant domestication was a substantial population increase. For describing its consequences there is a term - «Neolithic demographic transition» that lasted approximately 1500 years [2]. It describes the alleged exploding population grows in the period of Middle Pre-Pottery Neolithic in the Middle East. The most vivid manifestation of that process is considered to be such Neolithic mega-settlements as Ain Ghazal and Bayda' in the Levant and Asikli Hoyuk and Catal Huyuk in Turkey. However, doubts as to the correct assessment of population and inhabited area of these sites have been gaining ground in the light of recent findings. It makes a major contribution to estimations of «Neolithic demographic transition».

In this matter there are two main problems related to the way of population estimate of the certain archaeological site at some stage - it is done by the survey of terrain by specialists and collection of ceramic fragments at the same time. Then, based on diagnostic signs they are classified to a particular stage of chronology. According to the density of the finds and data of the territory where they are circulated, specialists conclude as to the size of the area which was taken up by settlements at a given time. Thereafter, based on ethnographic data of the area or materially similar cultures, specialists make a simple multiplication of a land area by estimated population density. Another option might be counting some households, which are usually compared with some buildings (which can be classified as residential buildings) and multiplying them by many people in one household (which was taken from the same sources or with written evidence, if a substantial part of an archaeological site is excavated and there are data on magnetometry). But in the period under our consideration, there are no any sources or evidence. Therefore, this method is inaccurate in this particular case because such a long duration of chronological phases of the material culture does not provide us with the high reliability in the estimate of the population at one time or another.

There are peculiarities during the period under review. In Anatolia, they relate to the evaluation of data of Asikli-Hoyuk and other similar settlements. Not every building with signs of people's daily activities can be considered as a particular household and can be used as a unit of calculation. It is related to the fact that fireplaces there are only in certain buildings, while there are none in the space between houses. [3.p. 89-93] Consequently, only a building complex given the number of fireplaces can be considered as per unit. However, investigations of Akkermans in Tel Sebi Abyad gives hard evidence that significantly discredit the estimates of the population. They have enabled to make a clarification that simultaneous the area of tells was built only partially and the growth of a tell took place through the iterative process of abandonment and development its different parts. The lifespan of a building was about 17-25 years. [4] Available data suggest that some settlements of the Southern Levant and Mesopotamia (like Ain Ghazal and Tel Halaf) had a similar pattern of construction. Taken together, these data call into question their characteristics, such as Neolithic mega-villages with a population of several 
thousand, and bring them to the level of small settlements with a population of about several hundred - thousand and something. Based on the above, it is impossible to talk about the exploding population, for example, in the middle Pre-Pottery Neolithic B and particularly in the Southern Levant. Likewise, estimates of the population of subsequent periods shall be reduced and handled with care.

Estimates of the population of large settlements of the Middle East, as well as settlement hierarchy, are often citing as evidence of the increasing complexity. The factor, which calls them into question, is a semi-nomadic character of the population of the region under consideration. Such a way of living is a complex phenomenon because forms of population mobility of that period are badly reconstructed. That is why there are used modern ethnographic analogies of this region, which is highly contentious due to Bernbek's data lying in the fact that the arrival of the Turkic population radically changed forms of population mobility. [5] The problem is that small settlements, which were found during foot surveys and not excavated, probably are temporary camps. In doing so, it was camps of hunters up to the beginning of 7th century BC and camps of cattlemen after the domestication of animals and making them a primary source of nutrition. The existence of signs of all-season stay in a settlement is overwhelming evidence of this fact because such a form of mobility as living of population in the same place during a few years and moving afterward are possible.

Notably, after the emergence of pastoralism in the Middle East, they became a constant and very small part of the population in the archaeological data. However, its great importance is confirmed by data of analysis of skeletal remains of animals, among which goats and sheep form a major part.

Bringing intermediate results, we conclude that the process of conversion to agriculture became a significant innovation, however, its consequences were more modest for the population and took a long time - several thousand years. Furthermore, it was one of the major occupations of a significant part of the population, along with pastoralism. In doing so, the turnover of the population didn't let to exercise effective control, which would become the beginnings of direct bureaucratic administrating. Moreover, the way of living in such a population was characterized as heterarchy along with the absence of clear indications of material stratification and hereditary status. Further, climate characteristics of the Middle East have changed possible forms of production because of the climate variations, since average rainfall in this region is 250-300 millimeters of rain per year, which are necessary for maintaining of rain-fed agriculture, and below, which requires irrigation [6]. Consequently, the percentage of the population engaged in pastoralism and agriculture was significantly changing.

One aspect of the connection of the process of the Neolithic revolution and changes in society forms is ceramics. The importance of this phenomenon also should be re-think for several reasons: firstly, in the Middle East ceramics emerged not as an untidy and rough, what would be naturally for its foundational emergence, but as a high-quality burnt at once; secondly, originally applying of ceramics was not utilitarian in nature. Archaeological materials of Tell Sabi Abyad [7] and Tell Secker al-Aheimar [8] indicate remains of the oldest ceramics of this region. It is characterized by high quality, high firing temperature, and time-consuming in the process of its production. The context of its find involves the use of these ceramics for a non-utilitarian meaning, but certain special events [7, p.80-82]. Such a phenomenon is connected with the construction of receptacles 
of a similar form of other materials, for instance, from various types of stone. Nevertheless, the emergence of ceramics has not led to noteworthy changes in the organization of society. But the following stage of development of ceramics (when it became rough) is connected with a fact of the first documented use of milk by a human. [9] In this context, it is already possible to talk about the utilitarian meaning of such ceramics. The next type of ceramics had been reversed and became a subject, which required a significant amount of labor time - it is Halaf ceramics famous due to its complicated ornaments. Parallel to this, ceramics was becoming the main form of funerary equipment [10, p. 127]. This illustrates the ambiguity of consequences of technological innovation and different variants of its application, what prevents the possibility to draw firm conclusions about the role of certain phenomena of the past only on the existence of certain kind of findings.

However, what is the relationship between these phenomena and forms of social organization? The point is, that they are one of the material aspects on which specialists make judgments on the forms of organization of people. As a result, even minor changes in the available data are very important for building social models in the past. And as the Middle East reminds almost the best-known region, research on the emergence of institutions of society use data on social organization in it. Knowledge of such details is required for cross-cultural research because ignoring them undermines the validity of the researcher's findings. Moreover, in our view, using methods of mathematical modeling of such processes is highly doubtful, because the data (on the number of people of a region in ancient times, for instance), which are used there, are very approximate.

Keeping with the theme of the relationship between way of housekeeping and social organization in the Middle East, we turn to materials of the Ubeid and Late Chalcolithic. We consider the relationship between the semi-nomadic lifestyle of the part of the population and changes in the material signs of the complexity of society, which led to the emergence of the Sumerian civilization of the early dynastic period. The main and most notable change of the Ubeid was the increasing number and size of settlements, which indicates a gradual increase of the population and, perhaps, one of the cycles of resettlement of population [10, p. 12, 11, p. 1468]. The most ancient evidence of settlements in South Mesopotamia refers to that chronological period (the end of VII thousand B.C.) [12]. In doing so, the local population initially started irrigation farming, because local climatic conditions do not allow them to maintain rain-fed agriculture. Moreover, the South was the extensive marshland near the sea, because waters of the Persian Gulf were significantly further, than nowadays, which enabled the exploitation of rich marine resources. Initially, differences in material culture were significant, but they significantly decreased later. Nevertheless, the main centers of developments became not South Mesopotamia, but North Mesopotamia with Anatolia and south-western Iran. By the end of $\mathrm{V}$ thousand B.C., signs of specializations of handicrafts are beginning to emerge. Initially, in centers such as Yumektepe in Anatolia, relatively close to brass minefields, increasing quantities of copper products began appearing. [13, p. 56-57]This was especially true for daily tools [14].

Specialization in ceramics appeared similarly. Production of ceramics became the domain of specialized workshops. The emergence of denser 10-20 ha settlements with a permanent population led to qualitative changes in the system of redistribution. So, it is possible to distinguish styles of particular masters in materials of ceramics from Susa and 
works in the same style of beginning apprentices. This fact reflects the mass production [15].

The development of metallurgy and a general intensification of pre-existing business links led to other consequences, which had its impacts. So, large settlements (like Tell Brak and Hamoukar in north-eastern Syria) occur gradually in places, which were more remoted from cooper deposits, but located in their transit routes. Hamoukar provides a clue how these centers were formed: the settlement with low population density on the territory about 300 ha initially existed near, but later it was reduced to 17 ha, however, densely built-up [17]. Probably, the semi-nomadic population, which carried out transit functions, gradually settled in profitable places and proceed to farm.

The role of the semi-nomadic population was reflected in stuff found on the territory of present-day Iran. For instance, a cemetery of a highly mobile population dated 4600-4200 B.C. was discovered in the desert area of Lorestan. The funerary equipment included ceramics. There were Susa and Mesopotamian vessels. This reflects contacts of this group with a wide geographic range: from North Mesopotamia to Khuzestan. In doing so, the emergence of such groups of highly mobile populations synchronized with the appearance of rare objects like the lapis and the wide distribution of cooper. The cemetery is located in the region reach in copper ore [17, p. 20].

Another evidence of changes is a character of graves and funerary equipment. At the end of V - the early IV thousand B.C. different non-utilitarian goods (especially beads) became the main subject of graves instead of the prevailed earlier ceramic vessels. In doing so, jewelry of rare and/or hard-to-reach materials (such as lapis, azure, and gold) appeared. There is an interesting and ambiguous fact that rich child buries emerge at the same time. It could be evidence of the emergence of elite inherited status. However, at the same time, there are any buries of adults, which appeared later, and graves of the next period are known just in a few cases, as well as unknown buries with rich equipment [10, p. 284-288].

A reflection of started changes is Tall-e Bakun A, which is dated to the middle of $\mathrm{V}$ thousand B.C. Because of the small size of the settlement, there were discovered large storage facilities, which were sealed with clay and seals. Such practice refers to 4600 B.C. We cannot agree with Abbas Alizade, who attracted a large amount of modern ethnographic data and made a conclusion that there was a chiefdom. He refers this fact to the evidence of the existence of a hierarchical community. [17, p.85, 91-95] In our view, such conclusions are doubtful in the absence of other material features of the property stratification. Nevertheless, drawing parallels to another archaeological site from the North Mesopotamia - Tepe Gawra is not only relevant, but also, in general, it confirms the existence of settlements of the highly mobile population, where their stocks, craft centers and, perhaps, administrative centers of elites by the end of the period of the Late Eneolithic were concentrated. It is worth noting that these settlements were located on the periphery of Mesopotamia, at the points of the named paths from resource sources to large settled settlements. Perhaps, their development is one of the possible development trajectories of the population mobility, which we described earlier. In such a way, some changes showed the complexity of the social organization happened to approximately 3800-3700 B.C.

The next stage is changing the context of the application of stamps - they became a means of denoting property rights and their transmission during the exchange of goods 
within the transregional exchange network of the Late Chalcolithic. For instance, a clay bull with seal impressions of the local and alien population was found in Hacinebi, where enclaved residents of South Mesopotamia existed. It is noteworthy that seals in Hacinebi were made of clay originating from the Susa district and Deh Luran plateau, but not from the Uruk region [18]. Evidence of exchange activity and using seals in this regard in North Mesopotamia are the same. Furthermore, remains of the ceramic with symbols, which were classified as proto-writing, were found in Tell Brak. There are also clay tablets with seal impressions and notches (perhaps, for clay balls) were found. [19] It should be noted that these tablets are precursors of writing. The nature of early writing is also interpretable in this. It has an accounting nature to control the exchange of goods exactly through the system of transregional exchange, but not only demands of local administrating of the economy.

In our view, this could suggest that the center, where appropriate technologies have emerged, were not prerogative of the South Mesopotamia centers. Centers like Susa were abandoned and there is evidence of a significant decline in the population in that region [20]. So, it is highly probable that these technologies have been expanded due to the impact of migration from the mentioned region.

It is worth considering, that significance of Uruk and archaeological items of the socalled «the Quarter of Eanna» and the role given to him in interpreting the material of the Late Chalcolithic in the Middle East, in our view, is quite exaggerated, and not only because of discoveries in Syria. Such criticism is based on the fact that monumental architecture of «the Quarter of Eanna» existed just within the stratigraphic layer of the Uruk 4a. This means, that they existed approximately a century [21]. Such an assessment is rough because there were any methods of dating (like carbon dating) at the time of excavation. Moreover, discoveries of stamps and tablets were regarded as debris, which was introduced to fill up the volume after the deliberate destruction of buildings. It does not let define the context of using of such findings. In our opinion, it is important, that images of the so-called «king -priest» are extremely similar among themselves. This fact distinguishes them from later monuments. Perhaps, this is the image of a supernatural creature. In the light of the above information, we conclude, that we do not have enough convincing materials, which would indicate the emergence of centralized hierarchical forms of social organization and especially developed bureaucracy exactly in the South Mesopotamia in the middle - the end IV thousand B.C. Evidence of lists of posts and professions are insufficient because translations of texts from Uruk of this period are carried out based on monuments of writing, which are later by almost a thousand years and even then they are not fully understood.

The total sunset of the Late Chalcolithic was caused by problems arising from the long-term aridization of climate. The following dawn of the age (including growth in the size of the settlements) occurred in the Early Dynastic Period, as well as the emergence of the institution of lugals as rulers of towns. Apparently, as in the case with Neolithization, building sustainable traditions of governance institutions requires a fairly long time.

Therefore, we have demonstrated that more gradual growth of population occurred in the Middle East. It is postulated within the Neolithic demographic transition concept. Measuring the population of the Middle East regions is complicated by the fact that some parts of the population had a highly-mobile lifestyle, which can be called semi-nomadic. 
That is why periods of aridization of the climate led not only to the general population decline but also to an increase in the share of the highly-mobile part of the population.

Consequently, these factors played a key role in the complexity of society, because they ensured long-range barter. This does not exclude the impact of the river trade. But at that time there are no known facts of finding its evidence in the period under view. The role of exchange networks is also quite important because evidence of their intensification (especially in connection with the development of the metallurgy) is in sync with the steady regional trend towards specialization of handicrafts, the first evidence of using of stamps in the context of administrating, the emergence of rich burials and other signs of wealth inequality.

\section{List of sources}

1. Kaner S, Taniguchi Y (2017) The development of pottery and associated technological developments in Japan, Korea, and the Russian Far East. Handbook of East and Southeast Asian Archaeology, eds Habu J, Lape P, Olsen J (Springer, New York).

2. Kuijt, Ian. (2008). Demography and Storage Systems During the Southern Levantine Neolithic Demographic Transition. 10.1007/978-1-4020-8539-0_11.

3. During, Bleda. (2006). Constructing Communities: Clustered Neighbourhood Settlements of the Central Anatolian Neolithic ca. 8500-5500 cal. BC. Nederlands Instituut Voor het Nabije Oosten.

4. Akkermans, Peter. (2013). Living Space, Temporality and Community Segmentation: Interpreting Late Neolithic Settlement in Northern Syria//Interpreting the Late Neolithic of Upper Mesopotamia, Publisher: Brepols, Editors: O. Nieuwenhuyse, R. Bernbeck, P.M.M.G. Akkermans \& J. Rogash, pp.63-75.

5. Bernbeck, Reinhard. (2008). An Archaeology of Multisited Communities. In: Barnard H. and Wendrich W. (eds.), The Archaeology of Mobility: Old World and New World Nomadism. Los Angeles: Cotsen Institute of Archaeology, pp. 43-77.

6. Simmons, A. (2000). Villages on the Edge: Regional Settlement Change and the End of the Lev-antine Pre-pottery Neolithic. In I. Kuijt (Ed.), Life in Neolithic Farming Communities: Social Organization, Identity, and Differentiation. New York: Kluwer/Plenum Press, pp. 211-230.

7. Nieuwenhuyse, O., Akkermans, P., \& Plicht, J. (2010). Not so coarse, nor always plain - the earliest pottery of Syria. Antiquity, 84(323), pp.71-85. doi:10.1017/S0003598X00099774

8. Bader, N., Le Mière, M. From Pre-Pottery Neolithic to Pottery Neolithic iN the Sinjar//Interpreting the Late Neolithic of Upper Mesopotamia, Publisher: Brepols, Editors: O. Nieuwenhuyse, R. Bernbeck, P.M.M.G. Akkermans \& J. Rogash, pp.513-520.

9. Nieuwenhuyse, Olivier \& Roffet-Salque, Mélanie \& Evershed, Richard \& Akkermans, Peter \& Russell, Anna. (2015). Tracing pottery use and the emergence of secondary product exploitation through lipid residue analysis at Late Neolithic Tell Sabi Abyad (Syria). Journal of Archaeological Science. 64. 54-66. 10.1016/j.jas.2015.10.002.

10. Brereton, GD; (2011) The social life of human remains: burial rites and the accumulation of capital during the transition from Neolithic to urban societies in the Near East. Doctoral thesis, UCL (University College London).

11. Akkermans, Peter. (2014). Settlement and Emergent Complexity in Western Syria, ca. 7000-2500 BC // C. Renfrew \& P. Bahn (eds), The Cambridge World Prehistory. Cambridge: Cambridge University Press, pp. $1462-1473$.

12. The Ubaid Period (5500-4000 B.C.) Electronic source: https://www.metmuseum.org/toah/hd/ubai/hd_ubai.htm (date of access 06.09.2020)

13. Kepinski C., Dessène F., Herveux L. 2011 - New evidence from Grai Resh, Northern Iraq, the 2001 and 2002 seasons. A pre-Uruk expansion site from the Late Chalcolithic period, Zeitschrift für OrientArchäologie 4, pp. 26-81

14. Yalçin, Ünsal. (2000). Frühchalkolitische Metallfunde von Mersin - Yumuktepe: Beginn der Extraktiven Metallurgie?. Türkiye Bilimler Akademisi Arkeoloji Dergisi. 3, pp. 109-128. 10.22520/tubaar.2000.0006.

15. Hole Frank. The Organization of Ceramic Production during the Susa I Period. In: Paléorient, 2010, vol. $36, n^{\circ} 1$. pp. 23-36. 
16. Ur, Jason A. 2017. "The Birth of Cities in Ancient West Asia." Ancient West Asian Civilization: Geoenvironment and Society in the Pre-Islamic Middle East, edited by Akira Tsuneki, Shigeo Yamada, and Kenichiro Hisada. Singapore: Springer, pp. 133-147.

17. Alizadeh, Abbas. 2006. The Origins of State Organizations in Prehistoric Highland Fars, Southern Iran: excavations at Tall-e Bakun. Chicago: Oriental Institute of the University of Chicago in association with the Iranian Cultural Heritage and Tourism Organization.

18. Blackman M. J. Chemical Characterization of Local Anatolian and Uruk Style Sealing Clays from Hacinebi. In: Paléorient, 1999,vol. 25, n 1 . L'expansion urukéenne : perspectives septentrionales vues à partir de Hacinebi, Hassek Höyük et Gawra. pp. 51-56.

19. Oates, J. (2002). Tell Brak: the 4th millennium sequence and its implications. In J. N. Postgate (ed.), Artefacts of Complexity, BSAI. pp. 111-121.

20. Hole, Frank. "A Monumental Failure: The Collapse of Susa." In Robin A. Carter and Graham Philip, eds., Beyond the Ubaid: Transformation and Integration of Late Prehistoric Societies of the Middle East, 221-226. Studies in Oriental Civilization, no. 653. Chicago: Oriental Institute of the University of Chicago, 2010.

21. Nissen, Hans J., Uruk: key site of the period and key site of the problem: Postgate, J.N. (Hg.), Artefacts of Complexity: Tracking the Uruk in the Near East (Iraq Archaeological Reports 5. 2002), pp. 1-16.

Кошман В. А. Факторы происхождения государственности в Юго-Западной Азии в период неолита и энеолита // Scientific notes of V. I. Vernadsky crimean federal university. Juridical science. 2021. - T. 7 (73). № 1. - P. 49-56.

Указывается, что процесс начального государствообразования происходил в северной Месопотамии. Также в статье рассматриваются некоторые утверждения по поводу возникновения оседлого образа жизни и скотоводства. Автор выделяет ключевые проблемы в оценках населения в древности в Юго-Западной Азии. Новые данные корректируют оценки населения на степень. Одной из ведущих статьи является роль высокомобильной части населения в функционировании межрегиональной торговли. Подчёркивается, что роль Урука существенно переоценена и ей не достает серьезных доказательств. Автор знакомит с новым подходом к пониманию происхождения государственности. Он произведен на основании материальных данных и аккуратном рассмотрении археологических интерпретаций.

Ключевые слова: неолитизация, государственность, Юго-Западная Азия, экспансия Урука, Халаф, полукочевники, Иранское плато. 